\title{
Understanding socio-economic inequalities in the prevalence of asthma in India: an evidence from national sample survey 2017-
} 18

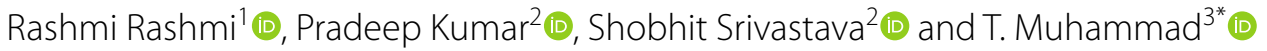

\begin{abstract}
Background: Today, over 300 million people reside with asthma worldwide and India alone is home for $6 \%$ of children and $2 \%$ of adults suffering from this chronic disease. A common notion of disparity persists in terms of health outcomes across the poor and better-off section of the society. Thus, there is a need to explore socio-economic inequality in the contribution of various factors associated with asthma prevalence in India.
\end{abstract}

Methods: Data for the study were carved out from the 75th round of National Sample Survey (NSS), collected by the National Sample Survey Organization (NSSO) during 2017-18. The sample size for this study was 555,289 individuals, for which data was used for the analysis. Descriptive statistics were used to show the distribution of the study population. Further, bivariate and multivariate analysis was performed to identify the factors associated with Asthma prevalence. The concentration index was used to measure the inequality. Further, we used decomposition analysis to find the contribution of factors responsible for socio-economic status-related inequality in asthma prevalence.

Results: The prevalence of asthma was 2 per 1000 in the whole population; however, the prevalence differs by age groups in a significant manner. Age, sex, educational status, place of residence, cooking fuel, source of drinking water, household size and garbage disposal facility were significantly associated with asthma prevalence in India. It was found that asthma was more concentrated among individuals from higher socioeconomic status (concentration index: $0.15 ; p<0.05)$. While exploring socio-economic inequality for asthma, richest wealth status (53.9\%) was the most significant contributor in explaining the majority of the inequality followed by the urban place of residence (37.9\%) and individual from age group 45-65 years (33.3\%). Additionally, individual aged 65 years and above (27.9\%) and household size less than four members (14.7\%) contributed in explaining socio-economic inequality for asthma.

Conclusion: Due to the heterogeneous nature of asthma, associations between different socio-economic indicators and asthma can be complex and may point in different directions. Hence, considering the concentration of asthma prevalence in vulnerable populations and its long-term effect on general health, a comprehensive programme to tackle chronic respiratory diseases and asthma, in particular, is urgently needed.

Keywords: Asthma; Socio-economic inequality; Decomposition; India

*Correspondence: muhammad.iips@gmail.com

${ }^{3}$ Department of Population Policies and Programmes, International Institute for Population Sciences, Mumbai, India

Full list of author information is available at the end of the article

\section{Background}

With the passage of time and changing lifestyles, the world is combating the growing threat of non-communicable diseases (NCDs). According to the World Health 
Organization (WHO), NCDs are responsible for $71 \%$ of all deaths worldwide [1] and adds substantial health and economic burden to nations that are already battling communicable and infectious diseases. In India, Global Burden of Disease (GBD) Collaborators showed a statelevel variation in epidemiological transition and found that the burden of NCDs like cardiovascular diseases, respiratory diseases and diabetes had escalated at an alarming rate [2]. While the contribution of cardiovascular diseases in total mortality of India was found to be the largest [3], the prevalence of respiratory disease named asthma had also increased by $8.6 \%$ during $1990-2016$ [4]. According to the definition of WHO, Asthma is a chronic or long term condition that inflames and narrows the airways in the lungs from time to time causing chest tightness, shortness of breath, wheezing and coughing [5]. Today, over 300 million people reside with asthma worldwide [6] and India alone is home for $6 \%$ of children and $2 \%$ of adults suffering from this chronic disease [7].

Although Asthma contributes a smaller burden of total mortality among non-communicable diseases, it still poses a serious concern as most of the deaths caused are preventable [8]. With no exact cure, this disease can be triggered through genetic and environmental factors. An Australian cross-sectional study found that asthma among children was highly associated with the direct and indirect effect of genetics, environment and allergens [9]. A longitudinal cohort study from Tucson provides evidence that chronic asthma among adults was highly associated with their onset from childhood and persistent wheezing in early life [10]. Past research had also indicated that early onset of asthma was linked with age [11], sex [12], genetic factors [13], parental smoking [14], active smoking in childhood [15], preterm birth [16], larger families [17] and childhood obesity [18]. Besides these factors, few psychological determinants were significantly linked with asthma among individuals [19].

Extant research from India has shown the prevalence, trend, socio-economic, demographic and environmental predictors of asthma morbidity across different sections of the population [20-23]. A study using the second round of India Human Development Survey data linked the burden of asthma with households using unclean fuels, individuals who are lesser educated and those who belong to a poorer section of society [24]. Further, a study had shown the role of various occupations among adults in building the risk of four non-communicable diseases including asthma [23]. Studies had also linked the influence of stressful psychosocial circumstances and spatial heterogeneity with the asthma prevalence in India [25, 26].

Across developed and developing countries, the trend in asthma mortality has decreased with a steady increase in the prevalence in the past few years and the reasons for such increase are yet not defined [27]. Despite advancements in technology to diagnose and manage asthma in developed countries, a study from New York city reveals that poor housing condition, outdoor air pollution and noxious land uses can contribute higher incidence of asthma in urban neighbourhoods [28]. A study, further, revealed that adolescents residing in peri-urban areas of developing countries are more prone to asthma [29]. The same study shows that the history of cigarette smoking and indoor pollution increases the likelihood of reported and symptoms of asthma. This brings our attention to the situation of developing nations, which are already succumbed from infectious diseases and are continuously burdened with the people who are yet not diagnosed or are unaware with the risk they are carrying. The risk is, further, increased in a country like India where the burden of non-communicable diseases is escalating [30] along with a sharp rise in urban settlements of poor [31].

The rationale for the current analysis is as follows. First, despite having a minimal mortality, asthma remains to have constant threat due to no exact cure procedure. Moreover, the growing urbanization and industrialization and changing lifestyles have increased the chances of asthma prevalence in both poor and richer section of society. Second, so far minimal evidence from India had examined the extent of socioeconomic inequality in NCD prevalence especially asthma which remains to be highly dominating in both younger and older age groups of society [32]. Lastly, due to variations in geographical, environmental, social, economic and cultural factors across the states of India, a state-wise inequality in asthma prevalence among different socio-economic groups can present a reliable estimate across India. Therefore, as per the conceptual framework provided in Fig. 1, the current study aims to explore the factors associated with asthma and the contribution of those factors in socioeconomic inequality in the prevalence of asthma in India.

\section{Data and methods \\ Data source}

Data for this study were carved out from the 75th round of National Sample Survey (NSS), schedule 25.0 data on key indicators of Household social consumption in India: health, collected by the National Sample Survey Organization (NSSO) during 2017-18. The 75th round survey was aimed at generating basic quantitative information on the health sector. The NSS has adopted multistage stratified sampling design with census villages and urban blocks as the first-stage units for the rural and urban areas, respectively, and households as the second-stage units for ensuring regional and 


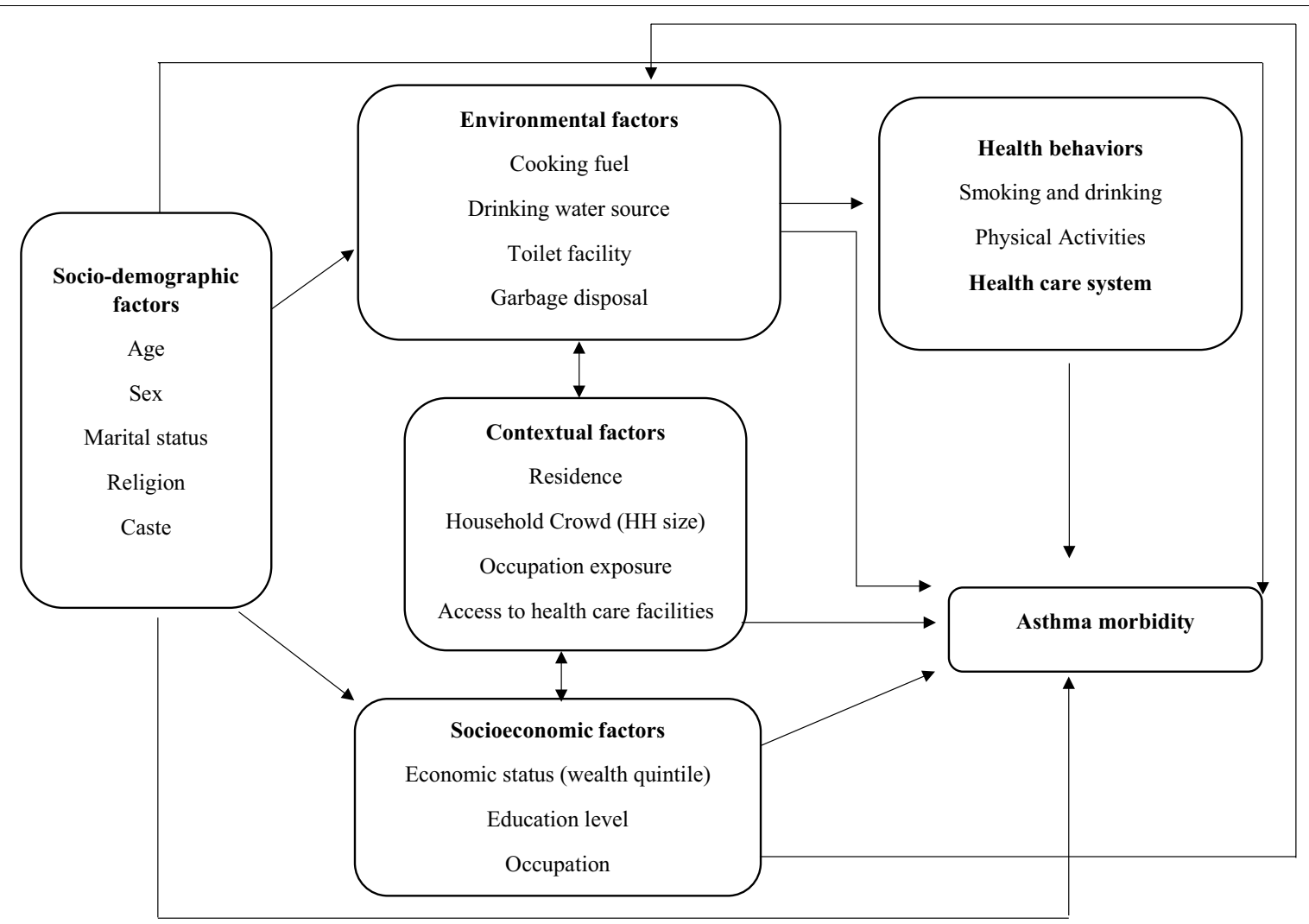

Fig. 1 Conceptual framework of asthma morbidity

social group representation. A detailed methodology of data collection and sampling design was published elsewhere [33]. The major objective of the survey was to determine the prevalence rate at the state and national level of general morbidity by age-group and gender, as well as of specific categories of ailment. The survey collected data from 555,372 individuals. We remove the missing cases ( 83 cases) from the data to provide better estimates. The sample size for this study was 555,289 individuals, for which data was used in the present study for the analysis.

\section{Outcome variable}

A direct question was asked to the respondent regarding the nature of ailment such as particular medical treatment received as an in-patient of a medical institution during the last 365 days 'Reported Diagnosis and/ or Main Symptom. The survey collected data about 89 diseases/symptoms of the household members. Asthma was the binary outcome variable of this study; if a person reported diagnosis of asthma it was coded as ' 1 ' and ' 0 ', otherwise.

\section{Exposure variables}

The predictor variables included age of the individual (less than 5, 5-14, 15-29, 30-44, 45-65, and 65+years), sex (male and female), marital status (never married, currently married and others), educational status (no education, below primary, primary and middle, secondary and above), religion (Hindu, Muslim, and others), caste (scheduled caste, scheduled tribe, other backward class, and others). The caste system in India has its roots in the earlier varna (color) system. The varnas represented a social hierarchy with purity and pollution-related notions, which is based on the principle that some works were considered pure and some impure or polluted. Accordingly, the system was setup to delegate the various activities to particular groups of people. Thus, the Scheduled Caste includes a group of the population that is socially and financially/economically segregated by their low status as per Hindu caste hierarchy. The Scheduled Castes (SCs) and Scheduled Tribes (STs) are among the most disadvantaged socio-economic groups in India. The OBC is is a group of intermediate categories identified as "educationally, economically and socially backward". The "other" caste category is identified as having 
higher social status [34, 35]. Place of residence (rural and urban), monthly per capita consumption expenditure (MPCE) (poorest, poorer, middle, richer, and richest), cooking fuel (clean and others), source of drinking water (improved and unimproved), type of toilet facility (improved and unimproved), household size (less than 4 members and 4 or more member), and garbage disposal (have an arrangement and no arrangement).

\section{Statistical analysis}

Descriptive statistics were used to show the distribution of the study population. Further, bivariate and multivariable analysis was used to identify the factors associated with Asthma. Moreover, wealth quintile was the key variable to measure the economic status of the household. To study the variation in asthma, health expenditure, choice of healthcare facility etc. across the population at different levels of living, a measure of the level of living was derived for each surveyed household based on information collected on its usual monthly consumer expenditure. This allowed estimates to be generated separately for 5 different equal-sized classes of the population at different quintile class of household expenditure and also known as monthly per capita consumption expenditure (MPCE) [36]. The study used household monthly per capita expenditure (Rupees) for decomposition analysis and the calculation of Concentration Index (CI), the study used MPCE which has divided into five equal sizes of the population.

\section{Concentration index}

Concentration index represents the magnitude of inequality by measuring the area between the concentration curve and line of equality and calculated as twice the weighted covariance between the outcome and fractional rank in the wealth distribution divided by the variable mean.

The concentration index can be written as follows:

$$
C=\frac{2}{\mu} \operatorname{cov}\left(y_{i}, R_{i}\right)
$$

where $\mathrm{C}$ is the concentration index; $y_{i}$ is the outcome variable index; $\boldsymbol{R}$ is the fractional rank of individual $\boldsymbol{i}$ in the distribution of socio-economic position; $\boldsymbol{\mu}$ is the mean of the outcome variable of the sample and cov denotes the covariance [37]. The index value lies between -1 to +1 .

If the curve lies above the line of equality, the concentration index takes a negative value, indicating a disproportionate concentration of inequality among the poor (pro-rich). Conversely, if the curve lies below the line of equality, the concentration index takes a positive value, indicating a disproportional concentration of inequality among the rich (pro-poor). In absence of socio-economic related inequality, the concentration index is zero.

\section{Decomposition of the concentration index}

The study used Wagstaff decomposition analysis to decompose the concentration index. Wagstaff's decomposition demonstrated that the concentration index could be decomposed into the contributions of each factor to the income-related inequalities [38]. Based on the linear regression relationship between the outcome variable $y_{i}$, the intercept $\alpha$, the relative contribution of $x_{k i}$ and the residual error $\varepsilon_{i}$

$$
y_{i}=\alpha+\sum \beta_{k} x_{k i}+\varepsilon_{i}
$$

where $\varepsilon_{i}$ is an error term, given the relationship between $y_{i}$ and $x_{k i}$, the CI for $\mathrm{y}(\mathrm{C})$ can be rewritten as:

$$
C=\sum\left(\frac{\beta_{k} \bar{x}_{k}}{\mu}\right) C_{k}+\frac{G C \varepsilon}{\mu} / \mu
$$

where $\mu$ is the mean of $y_{i}, \bar{x}_{k}$, is the mean of $x_{k}, \beta_{k}$ is the coefficient from a linear regression of outcome variable, $C_{k}$ is the concentration index for $x_{k}$ (defined analogously to $\mathrm{C}$, and $\mathrm{GC} \varepsilon$ is the generalized concentration index for the error term $\left(\varepsilon_{i}\right)$.

Here $\mathrm{C}$ is the outcome of two components: First, the determinants or 'explained' factors. The explained factors indicate that the proportion of inequalities in the outcome (Asthma) variable is explained by the selected explanatory factors, i.e., $\mathrm{x}_{\mathrm{k}}$. Second, a residual or 'unexplained' factor $\left(\frac{G C \varepsilon}{\mu} / \mu\right)$, indicating the inequality in health variable that cannot be explained by selected explanatory factors across various socioeconomic groups.

The analysis was adjusted for complex survey design (in this case multistage sampling) by using svyset command in STATA 14. The svyset command also adjusted the estimates for survey weights.

\section{Results}

Table 1 presents the socio-economic profile of the study population in India. About 3.3\% of the population belong to the age group 65 years and above. About $51.7 \%$ of the population was male and $48.3 \%$ was female. Nearly, $50.5 \%$ of the population was currently married and $44.4 \%$ was never married. Almost $26.1 \%$ of the population was not educated and $30.3 \%$ was having education secondary and above. About 8 in 10 people in India belong to the Hindu religion. About one-tenth of population was from the Scheduled Caste category and additionally, about 2 in 10 people belong to the Scheduled Caste category. About $70.5 \%$ of the population belong to a rural place of residence. Nearly $20.5 \%$ of the population belong to poorest 
Table 1 Socio-economic and demographic profile of study population, 2017-18

\begin{tabular}{|c|c|c|}
\hline Background characteristics & Percentage & Sample \\
\hline \multicolumn{3}{|l|}{ Age (in years) } \\
\hline$<5$ & 7.3 & 64,720 \\
\hline $05-14$ & 19.2 & 90,907 \\
\hline $15-29$ & 28.0 & $1,53,103$ \\
\hline $30-44$ & 22.1 & $1,16,038$ \\
\hline $45-65$ & 20.3 & $1,09,656$ \\
\hline $65+$ & 3.3 & 20,865 \\
\hline \multicolumn{3}{|l|}{ Sex } \\
\hline Male & 51.7 & $2,83,193$ \\
\hline Female & 48.3 & $2,72,096$ \\
\hline \multicolumn{3}{|l|}{ Marital status } \\
\hline Never married & 44.4 & $2,42,387$ \\
\hline Currently married & 50.5 & $2,86,022$ \\
\hline Others $^{\S}$ & 5.2 & 26,880 \\
\hline \multicolumn{3}{|l|}{ Educational status } \\
\hline No education"\# & 26.1 & $1,47,250$ \\
\hline Below primary & 16.4 & 84,648 \\
\hline Primary and middle & 27.3 & $1,41,734$ \\
\hline Secondary \& above & 30.3 & $1,81,657$ \\
\hline \multicolumn{3}{|l|}{ Religion } \\
\hline Hindu & 81.1 & $4,12,632$ \\
\hline Muslim & 14.1 & 83,047 \\
\hline Others $\$$ & 4.7 & 59,610 \\
\hline \multicolumn{3}{|l|}{ Caste group } \\
\hline Scheduled Tribe & 9.1 & 75,256 \\
\hline Scheduled Caste & 19.6 & 94,087 \\
\hline Other Backward Class & 44.9 & $2,22,876$ \\
\hline Others & 26.4 & $1,63,070$ \\
\hline \multicolumn{3}{|l|}{ Place of residence } \\
\hline Rural & 70.5 & $3,25,988$ \\
\hline Urban & 29.5 & $2,29,301$ \\
\hline \multicolumn{3}{|l|}{ MPCE } \\
\hline Poorest & 20.5 & $1,12,807$ \\
\hline Poorer & 21.1 & $1,12,365$ \\
\hline Middle & 19.1 & $1,02,645$ \\
\hline Richer & 19.5 & $1,05,701$ \\
\hline Richest & 19.9 & $1,21,771$ \\
\hline \multicolumn{3}{|l|}{ Cooking fuel } \\
\hline Clean $^{f}$ & 55.2 & $3,40,801$ \\
\hline Others & 44.8 & $2,14,488$ \\
\hline \multicolumn{3}{|l|}{ Source of drinking water } \\
\hline Improved $^{€}$ & 96.5 & $5,31,692$ \\
\hline Unimproved & 3.5 & 23,597 \\
\hline \multicolumn{3}{|l|}{ Type of toilet facility } \\
\hline Improved & 75.2 & $4,62,311$ \\
\hline Unimproved & 24.8 & 92,978 \\
\hline \multicolumn{3}{|l|}{ Household size } \\
\hline Less than 4 member & 17.0 & 68,129 \\
\hline 4 or more member & 83.0 & $4,87,160$ \\
\hline
\end{tabular}

Table 1 (continued)

\begin{tabular}{|c|c|c|}
\hline Background characteristics & Percentage & Sample \\
\hline \multicolumn{3}{|l|}{ Garbage disposal } \\
\hline Have arrangement & 41.0 & $2,68,077$ \\
\hline No arrangement & 59.0 & $2,87,212$ \\
\hline Total & 100.0 & $5,55,289$ \\
\hline \multicolumn{3}{|c|}{ MPCE Monthly per capita consumption expenditure } \\
\hline \multicolumn{3}{|c|}{ §Includes widow, separated and divorced } \\
\hline \multicolumn{3}{|c|}{${ }^{\#}$ No education also includes those who never attended school } \\
\hline \multicolumn{3}{|c|}{ \$Includes Christianity, Sikhism, Jainism, Buddhism, Zoroastrianism, and Others } \\
\hline \multicolumn{3}{|c|}{$\begin{array}{l}{ }^{\mathrm{E}} \text { Clean only includes LPG and Others includes firewood and chips, other natural } \\
\text { gas, dung cake, kerosene, coke, coal, gobar gas, other biogas, charcoal, no } \\
\text { cooking arrangement and others which were used for any purpose }\end{array}$} \\
\hline \multicolumn{3}{|c|}{$\begin{array}{l}{ }^{€} \text { Includes bottled water, piped water in dwelling/premises/yard, piped water } \\
\text { outside, tube-well/bore-well (inside or outside premise), protected well (inside } \\
\text { or outside premise), protected spring/pond and community RO plant }\end{array}$} \\
\hline${ }^{*}$ Includes flush/pour flush latrin & septic tar & \\
\hline
\end{tabular}

wealth quintile and $19.9 \%$ of the population belong to richest wealth quintile. Nearly, $55.2 \%$ of household used clean cooking fuel, $96.5 \%$ used improved source for drinking water and $75.2 \%$ used improved toilet facilities. About $83 \%$ of households had a household size of four or more. Nearly, $59 \%$ of households had no arrangement for garbage disposal.

Table 2 represents the prevalence of asthma and its logistic regression estimates by background characteristics in India. Only the logistic regression estimate will be interpreted as they provide the adjusted figures. Individuals aged $65+$ years had 67.92 times significantly higher likelihood to suffer from asthma in comparison to individuals less than five years [OR: 67.92; CI: 37.75-122.2]. Females had $14 \%$ significantly lower likelihood to suffer from asthma than males [OR: 0.86; CI: 0.76-0.98]. Individuals who were divorced/separated/widowed were $47 \%$ significantly higher likelihood to suffer from asthma in comparison to individuals from currently married status. Individuals with no educational status had $81 \%$ significantly higher likelihood to suffer from asthma than individuals who had secondary and above educational status [OR: 1.81; CI: 1.50-2.20]. Individuals from the Muslim religion had $29 \%$ significantly higher likelihood to suffer from asthma than individuals from Hindu religion [OR: 1.29; CI: 1.10-1.52]. Individuals from the urban place of residence had $45 \%$ significantly higher likelihood to suffer from asthma than individuals from a rural place of residence. The individual from Scheduled Tribe had 54\% lower likelihood to suffer from Asthma in reference to individuals from other caste category [OR: 0.46; CI: $0.34-0.61]$.

Further, individuals from richest wealth quintile had $76 \%$ significantly higher likelihood to suffer from asthma 
Table 2 Prevalence of Asthma and logistic regression estimates by background characteristics, 2017-18

\begin{tabular}{|c|c|c|}
\hline Background characteristics & $\begin{array}{l}\text { Prevalence } \\
\text { (per 1000) }\end{array}$ & OR $[95 \% \mathrm{Cl}]$ \\
\hline \multicolumn{3}{|l|}{ Age (in years) } \\
\hline$<5$ & 0.1 & Ref \\
\hline $05-14$ & 0.5 & $1.63 *(0.92-2.87)$ \\
\hline $15-29$ & 0.4 & $2.41^{* * *(1.39-4.18)}$ \\
\hline $30-44$ & 1.0 & $6.72^{* * *}(3.71-12.18)$ \\
\hline $45-65$ & 5.1 & $23.15^{* * *}(12.95-41.37)$ \\
\hline $65+$ & 17.3 & $67.92^{* * *}(37.75-122.2)$ \\
\hline \multicolumn{3}{|l|}{ Sex } \\
\hline Male & 2.0 & Ref \\
\hline Female & 2.1 & $0.86^{* *}(0.76-0.98)$ \\
\hline \multicolumn{3}{|l|}{ Marital status } \\
\hline Never married & 0.5 & $1.30(0.91-1.84)$ \\
\hline Currently married & 2.5 & Ref \\
\hline Others $^{\S}$ & 10.8 & $1.47^{* * *(1.26-1.72)}$ \\
\hline \multicolumn{3}{|l|}{ Educational status } \\
\hline No education"\# & 3.5 & $1.81^{* * *(1.50-2.20)}$ \\
\hline Below primary & 1.6 & $1.71^{* * *(1.36-2.15)}$ \\
\hline Primary and middle & 1.8 & $1.41^{* * *(1.17-1.69)}$ \\
\hline Secondary and above & 1.3 & Ref \\
\hline \multicolumn{3}{|l|}{ Religion } \\
\hline Hindu & 2.0 & Ref \\
\hline Muslim & 2.0 & $1.29^{* * *(1.10-1.52)}$ \\
\hline Others $\$$ & 2.5 & $0.79^{*}(0.62-1)$ \\
\hline \multicolumn{3}{|l|}{ Caste group } \\
\hline Scheduled Tribe & 1.4 & $0.46^{* * *}(0.34-0.61)$ \\
\hline Scheduled Caste & 2.4 & $1.01(0.84-1.21)$ \\
\hline Other Backward Class & 1.8 & $0.93(0.81-1.07)$ \\
\hline Others & 2.4 & Ref \\
\hline \multicolumn{3}{|l|}{ Place of residence } \\
\hline Rural & 1.9 & Ref \\
\hline Urban & 2.3 & $1.45^{* * *(1.24-1.69)}$ \\
\hline \multicolumn{3}{|l|}{ MPCE } \\
\hline Poorest & 1.5 & Ref \\
\hline Poorer & 1.9 & $1.19(0.96-1.47)$ \\
\hline Middle & 2.0 & $1.45^{* * *}(1.18-1.79)$ \\
\hline Richer & 2.0 & $1.46^{* * *}(1.18-1.8)$ \\
\hline Richest & 2.9 & $1.76^{* * *}(1.43-2.17)$ \\
\hline \multicolumn{3}{|l|}{ Cooking fuel } \\
\hline Clean ${ }^{\ddagger}$ & 2.0 & Ref \\
\hline Others & 2.1 & $1.37^{* * *(1.19-1.59)}$ \\
\hline \multicolumn{3}{|l|}{ Source of drinking water } \\
\hline Improved $^{€}$ & 2.0 & Ref \\
\hline Unimproved & 2.1 & $1.34^{* *}(1.03-1.75)$ \\
\hline \multicolumn{3}{|l|}{ Type of toilet facility } \\
\hline Improved $^{*}$ & 2.1 & Ref \\
\hline Unimproved & 1.9 & $0.94(0.79-1.13)$ \\
\hline \multicolumn{3}{|l|}{ Household size } \\
\hline Less than 4 member & 1.7 & $0.71^{* * *}(0.62-0.82)$ \\
\hline
\end{tabular}

Table 2 (continued)

\begin{tabular}{|c|c|c|}
\hline Background characteristics & $\begin{array}{l}\text { Prevalence } \\
\text { (per 1000) }\end{array}$ & OR $[95 \% \mathrm{Cl}]$ \\
\hline 4 or more member & 3.7 & Ref \\
\hline \multicolumn{3}{|l|}{ Garbage disposal } \\
\hline Have arrangement & 2.0 & Ref \\
\hline No arrangement & 2.1 & $1.13^{*}(0.98-1.3)$ \\
\hline Total & 2.0 & \\
\hline \multicolumn{3}{|c|}{$\begin{array}{l}\text { "if } p<0.01 * * \text { if } p<0.05 * * * \text { if } p<0.1 \text {; OR: Odds Ratio; Cl: Confidence Interval; } \\
\text { MPCE: Monthly per capita consumption expenditure }\end{array}$} \\
\hline \multicolumn{3}{|c|}{ Includes widow, separated and divorced } \\
\hline \multicolumn{3}{|c|}{${ }^{*}$ No education also includes those who never attended school } \\
\hline \multicolumn{3}{|c|}{${ }^{\$}$ Includes Christianity, Sikhism, Jainism, Buddhism, Zoroastrianism, and Others } \\
\hline \multicolumn{3}{|c|}{$\begin{array}{l}{ }^{\text {E}} \text { Clean only includes } L P G \text { and Others includes firewood and chips, other natural } \\
\text { gas, dung cake, kerosene, coke, coal, gobar gas, other biogas, charcoal, no } \\
\text { cooking arrangement and others which were used for any purpose }\end{array}$} \\
\hline \multicolumn{3}{|c|}{$\begin{array}{l}{ }^{\epsilon} \text { Includes bottled water, piped water in dwelling/premises/yard, piped water } \\
\text { outside, tube-well/bore-well (inside or outside premise), protected well (inside } \\
\text { or outside premise), protected spring/pond and community RO plant }\end{array}$} \\
\hline \multicolumn{3}{|c|}{${ }^{*}$ Includes flush/pour flush latrine to: piped sew, septic tank, pit latrine } \\
\hline
\end{tabular}

than individuals from poorest wealth quintile [OR: 1.76; CI: 1.43-2.17]. Individuals from the household with the unclean source of cooking fuel had $37 \%$ significantly higher likelihood to suffer from asthma than individuals from the household with a clean source of cooking fuel [OR:1.37; CI: 1.19-1.59]. Individuals from the household with an unimproved source of drinking water had $34 \%$ significantly higher likelihood to suffer from asthma than individuals from the household with an improved source of drinking water [OR: 1.34; CI: 1.03-1.75]. Individuals from the household with 4 or less members had $29 \%$ significantly lower likelihood to suffer from asthma than individuals from the household with 4 or more members [OR: 0.71; CI: 0.62-0.82].

Table 3 represents the state-wise prevalence and concentration index $(\mathrm{CCI})$ value for asthma in India. Daman and Diu had the highest prevalence of asthma (20.7\%) followed by Kerala (8.1\%) and West Bengal (4.9\%). Additionally, highest value for concentration index for asthma was for Chandigarh $(0.694 ; p<0.05)$ followed by Mizo$\operatorname{ram}(0.560 ; p<0.5)$ and West Bengal $(0.395 ; p<0.05)$.

Figure 2 reveals a concentration curve for asthma prevalence among the Indian population and it was found that asthma was more concentrated among individuals from higher socioeconomic status (CCI: $0.15 ; p<0.05$ ). The adjusted (Erreygers normalization) CCI was 0.005 .

Table 4 represents decomposition analysis estimates for asthma prevalence in India. Coefficients were obtained by applying logit regression. Absolute contribution is the product of elasticity and CCI whereas the percentage contribution is the proportion of absolute contribution multiplied by 100 . In explaining 
Table 3 State-wise prevalence and concentration index value for Asthma, 2017-18

\begin{tabular}{|c|c|c|c|}
\hline States & $\begin{array}{l}\text { Prevalence } \\
\text { (per 1000) }\end{array}$ & Index value & St. error \\
\hline Jammu \& Kashmir & 1.1 & -0.091 & 0.136 \\
\hline Himachal Pradesh & 3.1 & 0.102 & 0.103 \\
\hline Punjab & 3.6 & -0.116 & 0.074 \\
\hline Chandigarh & 3.0 & $0.694^{*}$ & 0.266 \\
\hline Uttarakhand & 1.3 & -0.140 & 0.176 \\
\hline Haryana & 0.9 & $0.254^{*}$ & 0.151 \\
\hline Delhi & 0.8 & $-0.557^{*}$ & 0.249 \\
\hline Rajasthan & 2.0 & $0.382^{*}$ & 0.077 \\
\hline Uttar Pradesh & 2.1 & 0.029 & 0.051 \\
\hline Bihar & 0.8 & 0.045 & 0.124 \\
\hline Sikkim & 0.2 & 0.455 & 0.694 \\
\hline Arunachal Pradesh & 0.4 & -0.048 & 0.312 \\
\hline Nagaland & 0.0 & - & - \\
\hline Manipur & 0.5 & -0.150 & 0.231 \\
\hline Mizoram & 1.0 & $0.560^{*}$ & 0.208 \\
\hline Tripura & 0.2 & 0.536 & 0.467 \\
\hline Meghalaya & 0.0 & - & - \\
\hline Assam & 0.8 & 0.076 & 0.154 \\
\hline West Bengal & 4.9 & $0.395^{*}$ & 0.047 \\
\hline Jharkhand & 1.6 & 0.104 & 0.115 \\
\hline Orissa & 2.0 & $0.378^{*}$ & 0.093 \\
\hline Chhattisgarh & 0.8 & $-0.298^{*}$ & 0.163 \\
\hline Madhya Pradesh & 1.3 & $0.174^{*}$ & 0.091 \\
\hline Gujarat & 1.5 & $0.298^{*}$ & 0.102 \\
\hline Daman \& Diu & 20.7 & 0.112 & 0.163 \\
\hline Dadra \& Nagar Haveli & 0.0 & - & - \\
\hline Maharashtra & 2.0 & $-0.361^{*}$ & 0.061 \\
\hline Andhra Pradesh & 2.9 & 0.075 & 0.082 \\
\hline Karnataka & 0.7 & -0.004 & 0.142 \\
\hline Goa & 0.3 & 0.792 & 0.706 \\
\hline Lakshadweep & 0.4 & 0.966 & 0.871 \\
\hline Kerala & 8.1 & 0.032 & 0.045 \\
\hline Tamil Nadu & 1.2 & 0.129 & 0.101 \\
\hline Pondicherry & 0.0 & - & - \\
\hline Andaman \& Nicobar Island & 0.6 & 0.638 & 0.505 \\
\hline Telangana & 1.8 & $-0.281^{*}$ & 0.112 \\
\hline
\end{tabular}

St. Error Standard error; *if $p<0.05$

socio-economic inequality for asthma, richest wealth status (53.9\%) was the most significant contributor in explaining the majority of the inequality followed by the urban place of residence $(37.9 \%)$ and individual from age group 45-65 years (33.3\%). Additionally, individual aged 65 years and above (27.9\%) and household size less than four members (14.7\%) contributed in explaining socio-economic inequality for asthma.

\section{Discussion}

There is a common notion that some disparities persist in terms of health outcomes across the poor and better-off section of society. And the problem intensifies when individuals are left undiagnosed due to lack of awareness and access to health care services. Ample evidence revealed that changing lifestyles and growing level of stress in dayto-day life easily triggers asthma in the richer section of society [39-41]. Thus, the study explored the factors associated and socio-economic inequality in the asthma prevalence and the contribution of various factors in those inequalities in India. Additionally, we have shown significant differences in state-wise prevalence rates of asthma in India.

The study reported that females had lower asthma prevalence as compared to males. In general, childhood asthma prevalence is higher in boys than in girls (especially before puberty). However, asthma prevalence becomes more prevalent in female than in males in adulthood. The inconsistent finding of our study can be a result of not stratifying by age groups while analysing the gender factor. We have also highlighted an unexpected pattern of higher prevalence of asthma among individuals with higher economic status measured by MPCE. The finding is contrary to many Western studies that showed that poor economic status and low income as risk factors for the development of asthma, asthmatic wheeze and chronic productive cough [42-44]. It is revealed that the higher prevalence of asthma found in poor compared to the affluent population in developed nations and in affluent compared to poor population in developing nations, reflects cultural and contextual differences [45]. The increased access to healthcare among people with higher economic status may explain the current finding where improved healthcare system contributes to the ascertainment of diseases such as asthma among the economically better-off populations. Studies also reported the higher likelihood of under-diagnosis and under-reporting of non-communicable diseases including asthma among lower socioeconomic groups in India [32].

Consistent with previous studies [43, 46], the contribution of educational status in the socioeconomic inequality in asthma prevalence was higher than any other socioeconomic variables in the study. The results are also in accordance with several studies that found the low educational level to be strongly associated with asthma and respiratory symptoms [42, 44, 47]. Importantly, the positive association of wealth quintile with asthma prevalence and simultaneously the negative association 


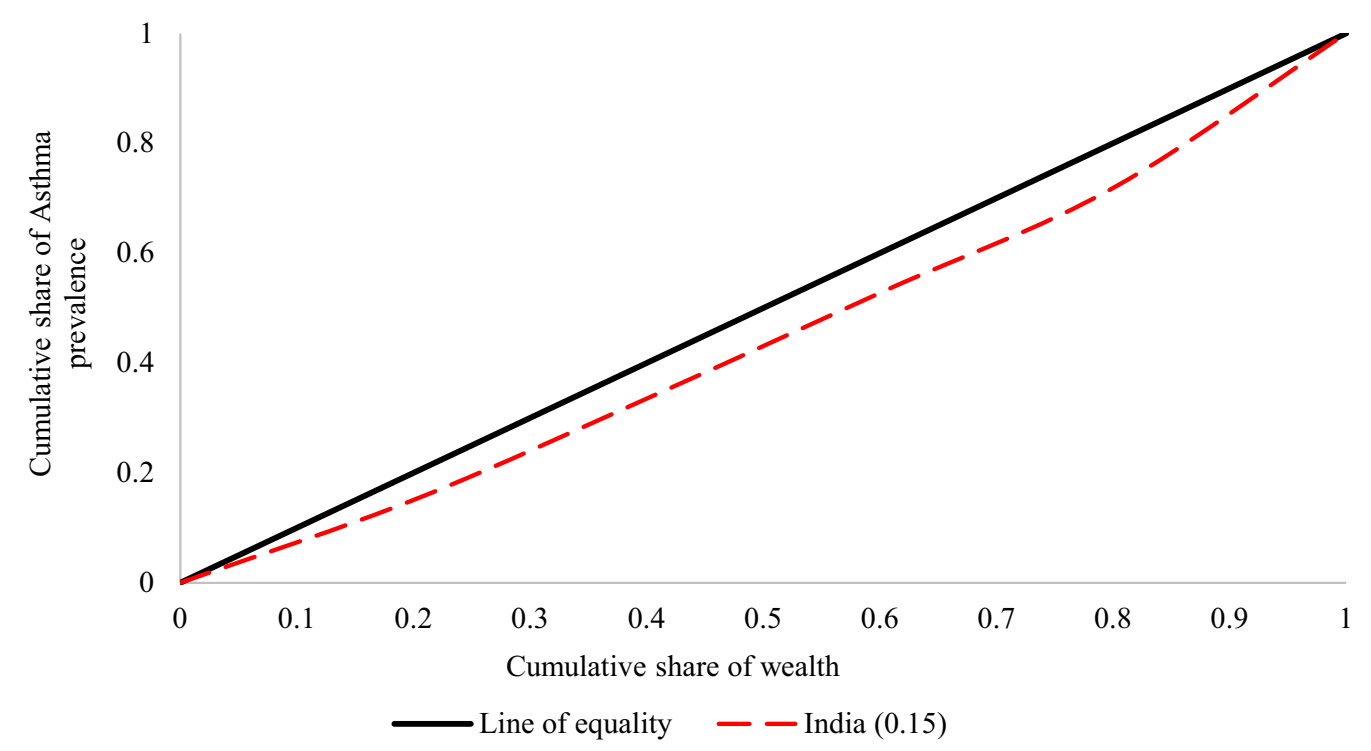

Fig. 2 Concentration curve for Asthma prevalence among the Indian population, 2017-18

of education with asthma in the current analysis suggest future investigation of underlying mechanisms in such associations. Further, the finding that higher the size of household greater the prevalence of asthma is inconsistent with previous studies that reported the inverse association of the number of siblings with the prevalence of asthma and called it as 'sibling effect' [48, 49]. Similarly, odds of suffering from asthma was higher among men than women in our study which is contrary to several earlier studies in India that revealed a higher prevalence of the disease among women who are more exposed to poor housing conditions [50,51]. Besides, urban rates of asthma prevalence were higher than rural rates in our study which confirms the finding that urbanization by which exposure to biomass fuel smoke increases is an environmental risk factor of asthma [52].

In a country where large proportion of the population still relies on solid and biomass fuels for cooking, a significant association was found between cooking fuel and the prevalence of asthma disease in the present study. It is found that clean cooking fuel is a protective factor against asthma which is consistent with earlier studies [51, 53, 54]. Further, an increased risk of asthma was found among the people from households that have no garbage disposal arrangements. Another study that evaluated the prevalence of asthma in relation to a residence in houses built on a former dumping area containing industrial and household wastes has shown similar finding that the risk of asthma was higher in the dump cohort than people living outside the site [55]. Consistent with a recent study in India
[26], a significant association of improved source of drinking water with lower asthma prevalence was also found in the present study which is supported by evidence that shows exposure to heavy metals and arsenic in drinking water increase the prevalence of respiratory illnesses [56-58]. Other potential mechanisms for such associations including the exposure to allergens need to be further explored in future studies.

The highest prevalence of asthma in the coastal states of Kerala, and West Bengal and the UT of Daman\& Diu may be attributed to its geographical features, where people consume more fish that may contribute to the higher burden of asthma in these States/UT [51]. We also found a relative difference between the lowest and highest region-wise prevalence rates that ranged between 0 to 20.7 individuals suffering from asthma per thousand individuals indicating that there are wide regional variations in the prevalence of asthma in India. Although the similar findings are shown in previous studies $[26,51]$, the reasons for the variations are unclear and require further investigation.

Large nationally representative sample is the strength of our study, which allows comparisons between states and urban-rural settings, and the ability to examine socioeconomic and housing patterns of asthma risk. However, the study is limited by its cross-sectional design. Additionally, biological or social factors related to asthma were not measured in this study which may have influenced and contributed to the gender and place of residence-related differences observed. Besides, the higher prevalence of asthma in older age groups in comparison 
Table 4 Decomposition analysis estimates for asthma prevalence among Indian population, 2017-18

\begin{tabular}{|c|c|c|c|c|c|c|}
\hline Background characteristics & Coefficients & Elasticity & $\mathrm{Cl}$ & $\begin{array}{l}\text { Absolute } \\
\text { contribution }\end{array}$ & \%contribution & Total contribution \\
\hline \multicolumn{7}{|l|}{ Age (in years) } \\
\hline \multicolumn{7}{|l|}{$<5$} \\
\hline $05-14$ & 0.49 & 0.000 & -0.115 & 0.000 & -4.7 & \multirow[t]{5}{*}{61.0} \\
\hline $15-29$ & 0.88 & 0.000 & 0.012 & 0.000 & 1.0 & \\
\hline $30-44$ & 1.91 & 0.000 & 0.028 & 0.000 & 3.5 & \\
\hline $45-65$ & 3.14 & 0.001 & 0.081 & 0.000 & 33.3 & \\
\hline $65+$ & 4.22 & 0.001 & 0.136 & 0.000 & 27.9 & \\
\hline \multicolumn{7}{|l|}{ Sex } \\
\hline \multicolumn{7}{|l|}{ Male } \\
\hline Female & -0.15 & 0.000 & -0.001 & 0.000 & 0.0 & 0.0 \\
\hline \multicolumn{7}{|l|}{ Marital status } \\
\hline Never married & 0.26 & 0.000 & -0.047 & 0.000 & -3.9 & 1.6 \\
\hline \multicolumn{7}{|l|}{ Currently married } \\
\hline Others $^{\S}$ & 0.39 & 0.000 & 0.067 & 0.000 & 5.5 & \\
\hline \multicolumn{7}{|l|}{ Educational status } \\
\hline No education ${ }^{\#}$ & 0.60 & 0.000 & -0.169 & 0.000 & -13.9 & -19.9 \\
\hline Below primary & 0.54 & 0.000 & -0.095 & 0.000 & -3.9 & \\
\hline Primary and middle & 0.34 & 0.000 & -0.051 & 0.000 & -2.1 & \\
\hline \multicolumn{7}{|l|}{ Secondary above } \\
\hline \multicolumn{7}{|l|}{ Religion } \\
\hline \multicolumn{7}{|l|}{ Hindu } \\
\hline Muslim & 0.25 & 0.000 & -0.035 & 0.000 & -1.4 & -1.4 \\
\hline Others $^{\$}$ & -0.24 & 0.000 & 0.291 & 0.000 & 0.0 & \\
\hline \multicolumn{7}{|l|}{ Caste group } \\
\hline Scheduled Tribe & -0.79 & 0.000 & -0.301 & 0.000 & 0.0 & -5.2 \\
\hline Scheduled Caste & 0.01 & 0.000 & -0.149 & 0.000 & -6.1 & \\
\hline Other Backward Class & -0.07 & 0.000 & -0.021 & 0.000 & 0.9 & \\
\hline \multicolumn{7}{|l|}{ Others } \\
\hline \multicolumn{7}{|l|}{ Place of residence } \\
\hline \multicolumn{7}{|l|}{ Rural } \\
\hline Urban & 0.37 & 0.000 & 0.462 & 0.000 & 37.9 & 37.9 \\
\hline \multicolumn{7}{|l|}{ MPCE } \\
\hline \multicolumn{7}{|l|}{ Poorest } \\
\hline Poorer & 0.17 & 0.000 & -0.257 & 0.000 & -10.6 & 57.4 \\
\hline Middle & 0.37 & 0.000 & 0.035 & 0.000 & 1.4 & \\
\hline Richer & 0.38 & 0.000 & 0.309 & 0.000 & 12.7 & \\
\hline Richest & 0.57 & 0.000 & 0.657 & 0.000 & 53.9 & \\
\hline \multicolumn{7}{|l|}{ Cooking fuel } \\
\hline \multicolumn{7}{|l|}{ Clean $^{f}$} \\
\hline Others & 0.32 & 0.000 & -0.277 & 0.000 & -22.7 & -22.7 \\
\hline \multicolumn{7}{|l|}{ Source of drinking water } \\
\hline \multicolumn{7}{|l|}{ Improved $^{\epsilon}$} \\
\hline Unimproved & 0.29 & 0.000 & -0.038 & 0.000 & 0.0 & 0.0 \\
\hline Type of toilet facility & & & & & & \\
\hline Improved $^{*}$ & & & & & & 0.0 \\
\hline Unimproved & -0.06 & 0.000 & -0.361 & 0.000 & 0.0 & \\
\hline Household size & & & & & & \\
\hline Less than 4 member & -0.34 & -0.001 & -0.060 & 0.000 & 14.7 & 14.7 \\
\hline 4 or More member & & & & & & \\
\hline
\end{tabular}


Table 4 (continued)

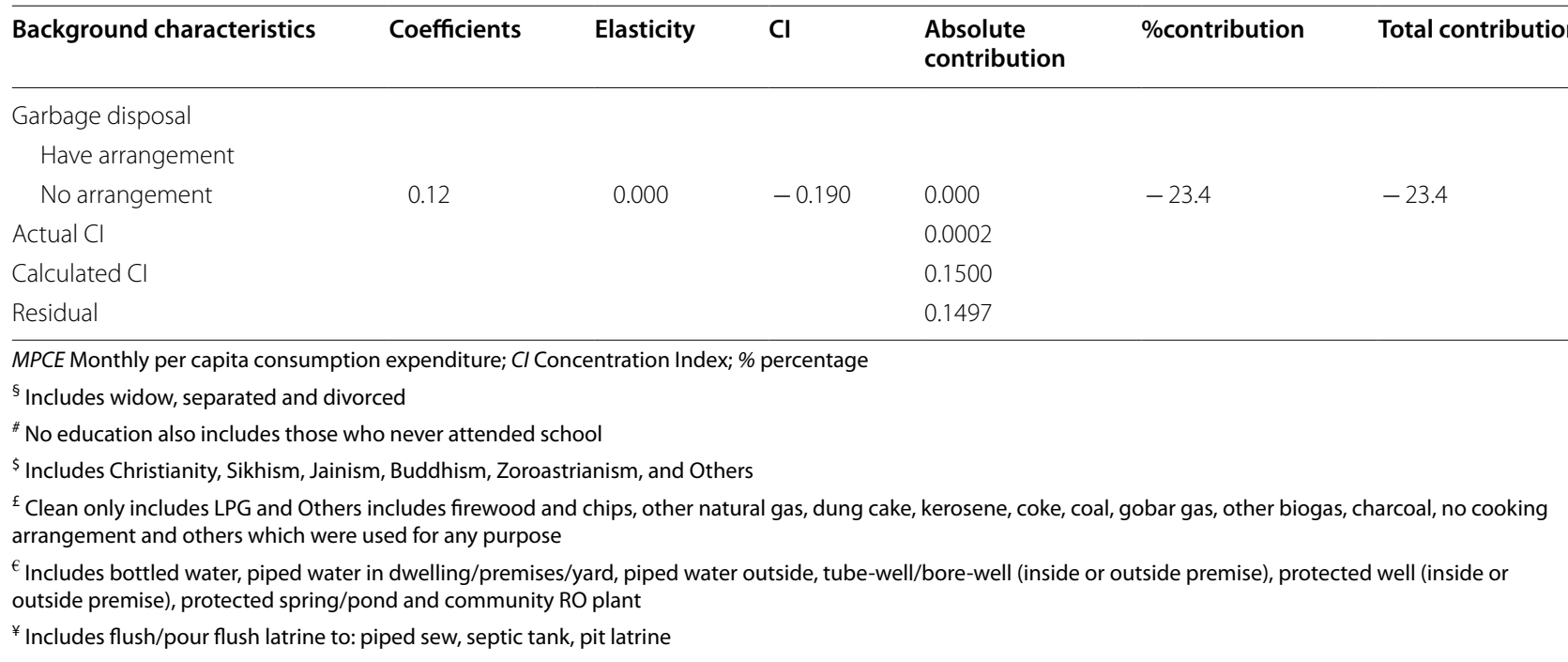

to younger population might be due to potential bias in reporting the disease such as potential misclassification between chronic obstructive pulmonary disease (COPD) and asthma in the older age groups.

\section{Conclusion}

Advancing age, male sex, residence in the urban area, lower education, higher MPCE and poor housing conditions such as unclean cooking fuel, unimproved source of drinking water and unarranged garbage disposal were associated with significantly higher odds of having asthma. Due to the heterogeneous nature of asthma, associations between different SES indicators and asthma can be complex and may point in different directions. Hence, considering the concentration of asthma prevalence in vulnerable populations and its long-term effect on general health, a comprehensive programme to tackle chronic respiratory diseases and asthma, in particular, is urgently needed.

Future studies are warranted on the higher prevalence of asthma among wealthy people observed in the current study. Besides, a state-specific analysis must be conducted to explore the substantial differences in asthma prevalence and different socioeconomic and environmental risk factors in Indian states. And further longitudinal studies should be conducted to confirm the temporal sequence of the results and further elucidate the impact of socioeconomic and contextual disadvantages on the incidence of asthma over the course of time.

Acknowledgements

Not applicable.
Authors' contributions

RR, PK, SS and MT made a substantial contribution to the concept, design of the work, acquisition, analysis and interpretation of data. RR, PK, SS and MT drafted the article or revised it critically for important intellectual content. RR, PK, SS and MT approved the version to be published. RR, PK, SS and MT each author have participated sufficiently in the work to take public responsibility for appropriate portions of the content. All authors read and approved the final manuscript.

\section{Funding}

Authors did not receive any funding to carry out this research.

Availability of data and materials

The study utilises secondary source of data which is freely available in public domain through http://mospi.nic.in/NSSOa.

\section{Declarations}

Ethics approval and consent to participate

Not applicable.

\section{Consent for publication}

Not applicable.

\section{Competing interests}

The authors declare that they have no competing interests.

\section{Author details}

${ }^{1}$ International Institute for Population Sciences, Mumbai, India. ${ }^{2}$ Department of Survey Research \& Data Analytics, International Institute for Population Sciences, Mumbai, India. ${ }^{3}$ Department of Population Policies and Programmes, International Institute for Population Sciences, Mumbai, India.

Received: 16 December 2020 Accepted: 9 November 2021 Published online: 15 November 2021

\section{References}

1. World Health Organization. Noncommunicable diseases [Internet]. 2018 [cited 2020 Dec 16]. Available from: https://www.who.int/health-topics/ noncommunicable-diseases\#tab=tab_1 
2. Dandona L, Dandona R, Kumar GA, Shukla DK, Paul VK, Balakrishnan K et al. India state-level disease burden initiative collaborators. Nations within a nation: Variations in epidemiological transition across the states of India 1990-2016 in the global burden of disease study. Lancet. 2017:390(10111):2437-60.

3. Prabhakaran D, Jeemon P, Sharma M, Roth GA, Johnson C, Harikrishnan S, et al. The changing patterns of cardiovascular diseases and their risk factors in the states of India: the Global Burden of Disease Study 1990-2016. Lancet Glob Heal. 2018;6(12):e1339-51.

4. Salvi S, Kumar GA, Dhaliwal RS, Paulson K, Agrawal A, Koul PA, et al. The burden of chronic respiratory diseases and their heterogeneity across the states of India: the Global Burden of Disease Study 1990-2016. Lancet Glob Heal. 2018;6(12):e1363-74.

5. WHO. Asthma Factsheets. World Health Organization. 2020.

6. Beasley R, Hancox RJ. Reducing the burden of asthma: time to set research and clinical priorities. Lancet Respir Med. 2020.

7. Global Asthma Network. The Global Asthma Report. 2018.

8. Sadatsafavi M, Rousseau R, Chen W, Zhang W, Lynd L, FitzGerald JM. The preventable burden of productivity loss due to suboptimal asthma control: a population-based study. Chest. 2014:145(4):787-93.

9. Gold DR, Wright R. Population disparities in asthma. Annu Rev Public Health. 2005;26(107):89-113.

10. Stern DA, Morgan WJ, Halonen M, Wright AL, Martinez FD. Wheezing and bronchial hyper-responsiveness in early childhood as predictors of newly diagnosed asthma in early adulthood: a longitudinal birth-cohort study. Lancet. 2008;372(9643):1058-64.

11. Guddattu V, Swathi A, Nair NS. Household and environment factors associated with asthma among Indian women: a multilevel approach. J Asthma. 2010;47(4):407-11.

12. Melgert BN, Ray A, Hylkema MN, Timens W, Postma DS. Are there reasons why adult asthma is more common in females? Curr Allergy Asthma Rep. 2007;7(2):143-50

13. Martinez FD. Genes, environments, development and asthma: a reappraisal. Eur Respir J. 2007;29(1):179-84.

14. Mitchell EA, Beasley R, Keil U, Montefort S, Odhiambo J, Group IPTS. The association between tobacco and the risk of asthma, rhinoconjunctivitis and eczema in children and adolescents: analyses from Phase Three of the ISAAC programme. Thorax 2012;67(11):941-9.

15. Gilliland FD, Islam T, Berhane K, Gauderman WJ, McConnell R, Avol E, et al. Regular smoking and asthma incidence in adolescents. Am J Respir Crit Care Med. 2006;174(10):1094-100

16. Sonnenschein-Van Der Voort AMM, Arends LR, de Jongste JC, AnnesiMaesano I, Arshad SH, Barros H, et al. Preterm birth, infant weight gain, and childhood asthma risk: a meta-analysis of 147,000 European children. J. Allergy Clin. Immunol. 2014;133(5):1317-29.

17. Strachan DP, Ait-Khaled N, Foliaki S, Mallol J, Odhiambo J, Pearce N, et al. Siblings, asthma, rhinoconjunctivitis and eczema: a worldwide perspective from the International Study of Asthma and Allergies in Childhood. Clin Exp Allergy. 2015;45(1):126-36.

18. Mitchell EA, Beasley R, Björkstén B, Crane J, Garcia-Marcos L, Keil U, et al. The association between $\mathrm{BMI}$, vigorous physical activity and television viewing and the risk of symptoms of asthma, rhinoconjunctivitis and eczema in children and adolescents: ISAAC Phase Three. Clin Exp Allergy. 2013;43(1):73-84.

19. Van Lieshout RJ, MacQueen G. Psychological factors in asthma. Allergy Asthma Clin Immunol. 2008;4(1):12.

20. To T, Stanojevic S, Moores G, Gershon AS, Bateman ED, Cruz AA, et al. Global asthma prevalence in adults: findings from the cross-sectional world health survey. BMC Public Health. 2012;12(1):204

21. Aggarwal AN, Chaudhry K, Chhabra SK, D Souza GA, Gupta D, Jindal SK, et al. Prevalence and risk factors for bronchial asthma in Indian adults: a multicentre study. Indian J. Chest Dis. Allied Sci. 2006;48(1):13.

22. Arokiasamy P, Karthick K, Pradhan J. Environmental risk factors and prevalence of asthma, tuberculosis and jaundice in India. Int J Environ Health. 2007;1 (2):221-42.

23. Patel S, Ram U, Ram F, Patel SK. Socioeconomic and demographic predictors of high blood pressure, diabetes, asthma and heart disease among adults engaged in various occupations: evidence from India. J Biosoc Sci. 2020;52(5):629-49.

24. Kumar P, Ram U. Patterns, factors associated and morbidity burden of asthma in India. PLoS ONE. 2017;12(10):e0185938.
25. Subramanian SV, Ackerson LK, Subramanyam MA, Wright RJ. Domestic violence is associated with adult and childhood asthma prevalence in India. Int J Epidemiol. 2007;36(3):569-79.

26. Singh SK, Gupta J, Sharma H, Pedgaonkar SP, Gupta N. Socio-economic correlates and spatial heterogeneity in the prevalence of asthma among young women in India. BMC Pulm Med. 2020;20(1):1-12.

27. Beasley R, Semprini A, Mitchell EA. Risk factors for asthma: Is prevention possible? Lancet. 2015;386(9998):1075-85.

28. Corburn J, Osleeb J, Porter M. Urban asthma and the neighbourhood environment in New York City. Health Place. 2006;12(2):167-79.

29. Robinson CL, Baumann LM, Romero K, Combe JM, Gomez A, Gilman RH, et al. Effect of urbanisation on asthma, allergy and airways inflammation in a developing country setting. Thorax. 2011;66(12):1051-7.

30. Arokiasamy P. India's escalating burden of non-communicable diseases. Lancet Glob Health. 2018;6(12):e1262-3.

31. Ooi GL, Phua KH. Urbanization and slum formation. J Urban Health. 2007;84(1):27-34.

32. Vellakkal S, Subramanian S V, Millett C, Basu S, Stuckler D, Ebrahim S. Socioeconomic inequalities in non-communicable diseases prevalence in India: Disparities between self-reported diagnoses and standardized measures. PLOS ONE. 2013;8(7):e68219.

33. National Sample Survey Office. Key Indicators of Social Consumption in India Health. Ministry of Statistics and Programme Implementation New Delhi; 2017.

34. Subramanian S V., Nandy S, Irving M, Gordon D, Lambert H, Smith GD. The mortality divide in India: The differential contributions of gender, caste, and standard of living across the life course. Am J Public Health. 2006.

35. Jensen R. Caste, culture, and the status and well-being of widows in India. Anal Econ Aging. 2005; (August):357-76.

36. Singh L, Arokiasamy P, Singh PK, Rai RK. Determinants of gender differences in self-rated health among older population: Evidence from India. SAGE Open. 2013;3(2):1-12.

37. O'donnell O, Van Doorslaer E, Wagstaff A, Lindelow M. Analyzing health equity using household survey data: a guide to techniques and their implementation. The World Bank; 2007.

38. Wagstaff A. Socioeconomic inequalities in child mortality: Comparisons across nine developing countries. Bull World Health Organ. 2000;78(1):19-28.

39. Nunes C, Pereira AM, Morais-Almeida M. Asthma costs and social impact. Asthma Res Pract. 2017;3(1):1-11.

40. Rodriguez A, Brickley E, Rodrigues L, Normansell RA, Barreto M, Cooper PJ. Urbanisation and asthma in low-income and middle-income countries: a systematic review of the urban-rural differences in asthma prevalence. Thorax. 2019;74(11):1020-30.

41. Barros R, Moreira A, Padrão P, Teixeira VH, Carvalho P, Delgado L, et al. Dietary patterns and asthma prevalence, incidence and control. Clin Exp Allergy. 2015;45(11):1673-80.

42. Hedlund U, Eriksson K, Rönmark E. Socio-economic status is related to incidence of asthma and respiratory symptoms in adults. Eur Respir J. 2006;28(2):303-10.

43. Chittleborough CR, Taylor AW, Dal Grande E, Gill TK, Grant JF, Adams RJ, et al. Gender differences in asthma prevalence: Variations with socioeconomic disadvantage. Respirology. 2010;15(1):107-14.

44. Schyllert C, Lindberg A, Hedman L, Stridsman C, Andersson M, Ilmarinen $P$, et al. Low socioeconomic status relates to asthma and wheeze, especially in women. ERJ Open Res. 2020;6(3):1-11.

45. GINA. Global Strategy for Asthma Management and Prevention: 2017 Guidelines. Vol. 126, Global Initiative for Asthma. 2017.

46. Sinharoy A, Mitra S, Mondal P. Socioeconomic and Environmental Predictors of Asthma-Related Mortality. J Environ Public Health. 2018;2018.

47. Eagan TML, Gulsvik A, Eide GE, Bakke PS. The effect of educational level on the incidence of asthma and respiratory symptoms. Respir Med. 2004;98(8):730-6.

48. Karmaus W, Botezan C. Does a higher number of siblings protect against the development of allergy and asthma? A review. J Epidemiol Community Health. 2002;56(1):209-17.

49. Farfel A, Tirosh A, Derazne E, Garty BZ, Afek A. Association between socioeconomic status and the prevalence of asthma. Ann Allergy Asthma Immunol. 2010;104(6):490-5. 
50. Mishra V. Effect of indoor air pollution from biomass combustion on prevalence of asthma in the elderly. Environ Health Perspect. 2003;111(1):71-8.

51. Agrawal S, Pearce N, Ebrahim S. Prevalence and risk factors for selfreported asthma in an adult Indian population: A cross-sectional survey. Int J Tuberc Lung Dis. 2013;17(2):275-82.

52. Gaviola C, Miele CH, Wise RA, Gilman RH, Jaganath D, Miranda JJ, et al. Urbanisation but not biomass fuel smoke exposure is associated with asthma prevalence in four resource-limited settings. Thorax. 2016;71(2):154-60.

53. Trevor J, Antony $\mathrm{V}$, Jindal SK. The effect of biomass fuel exposure on the prevalence of asthma in adults in India-Review of current evidence. J Asthma. 2014;51(2):136-41.

54. Agrawal S. Effect of indoor air pollution from biomass and solid fuel combustion on prevalence of self-reported asthma among adult men and women in India: Findings from a nationwide large-scale cross-sectional survey. J Asthma. 2012;49(4):355-65.

55. Pukkala E, Pönkä A. Increased incidence of cancer and asthma in houses built on a former dump area. Environ Health Perspect. 2001:109(11):1121-5.
56. Arain MB, Kazi TG, Baig JA, Jamali MK, Afridi HI, Jalbani N, et al. Respiratory effects in people exposed to arsenic via the drinking water and tobacco smoking in southern part of Pakistan. Sci Total Environ. 2009;407(21):5524-30.

57. Dauphiné DC, Ferreccio C, Guntur S, Yuan Y, Hammond SK, Balmes J, et al. Lung function in adults following in utero and childhood exposure to arsenic in drinking water: Preliminary findings. Int Arch Occup Environ Health. 2011;84(6):591-600.

58. Chowdhury S, Mazumder MAJ, Al-Attas O, Husain T. Heavy metals in drinking water: Occurrences, implications, and future needs in developing countries. Sci Total Environ. 2016;569-570:476-88.

\section{Publisher's Note}

Springer Nature remains neutral with regard to jurisdictional claims in published maps and institutional affiliations.
Ready to submit your research? Choose BMC and benefit from:

- fast, convenient online submission

- thorough peer review by experienced researchers in your field

- rapid publication on acceptance

- support for research data, including large and complex data types

- gold Open Access which fosters wider collaboration and increased citations

- maximum visibility for your research: over $100 \mathrm{M}$ website views per year

At BMC, research is always in progress.

Learn more biomedcentral.com/submissions 